\title{
Comparatives in Turkish Sign Language (TiD)
}

\author{
A. Sumru Özsoy \& Hüner Kaşıkara \\ Boğaziçi University
}

This study focuses on the comparative constructions in Turkish Sign Language (TID), the native language of the deaf in Turkey. We show that in terms of Stassen's (2013) typology, TiD uses two distinct constructions to express comparison: (i) Conjoined Comparatives, and (ii) Locational Comparatives. The Conjoined Comparative construction consists of two structurally independent clauses (one containing the standard, the second containing the comparee) where the NPs function as subjects of their respective clauses. In Locational Comparative constructions, a single predicate expresses the parameter shared by the participants. The two NPs are located in the signing space by indexing (IX) and body shift. Comparison between the two arguments is expressed by IX СОMP (the index of comparison). Given that directionality is one of the means that sign languages use to represent the relationship between verbs and their arguments (Lillo-Martin \& Meier 2011) and that the direction of the path movement of the manual sign is determined by the thematic roles of the arguments from the R-locus of the SOURCE argument to the R-locus of the GOAL argument in "backward agreement" contexts (Aronoff et al. 2005), we hold that the directionality of movement in the comparative construction in TID is parallel to the verbal agreement of sign languages.

\section{Introduction}

This study ${ }^{1}$ is a description of the basic properties of the comparative structures in Turkish Sign Language (TID), the native language of the deaf in Turkey. Sapir (1944: 95) states that "psychologically all comparatives are primary in relation to their corresponding absolutes ("positives')" and that "grading as a psychological process (...) precedes measurement and counting". Stassen (2013) proposed a typology of comparative constructions in spoken languages where he distinguishes four strategies that languages employ to express comparison: (i) Conjoined Comparatives, (ii) Nonconjoined (Particle) Comparatives, (iii) Locational Comparatives, and (iv) Exceed Comparatives, as exemplified below:

(i) Conjoined Comparative from Amele (Roberts 1987: 135, cited in Stassen 2013)

$\begin{array}{llllll}\text { jo } & \mathrm{i} & \text { ben } & \text { jo } & \text { eu } & \text { nag } \\ \text { house } & \text { this } & \text { big } & \text { House } & \text { that } & \text { small }\end{array}$

'This house is bigger than that house.'

(ii) Nonconjoined Comparative from French (Bernard Bichakjian p.c., cited in Stassen 2013) (2)

$\begin{array}{lllllll}\text { tu } & \text { es } & \text { plus } & \text { jolie } & \text { que } & \text { ta } & \text { sœur } \\ \text { you } & \text { are } & \text { more } & \text { pretty } & \text { than } & \text { your } & \text { sister } \\ \text { 'You are } & \text { prettier } & \text { than } & \text { your sister.' } & & & \end{array}$

\footnotetext{
${ }^{1}$ The research for this study was fully supported by the TÜBITAK project no $111 \mathrm{~K} 314$. We would like to extend our gratitude to TÜBITAK for supporting our project on TID. The project was also a member of the COST SIGNRAM project.
} 
(3)

(iii) Locational Comparative from Ahaggar Tuareg (Hanoteau' 1986: 52, cited in Stassen 2013) $\begin{array}{llllll}\text { kemmou } & \text { tehousid } & \text { foull } & \text { oult } & \text { ma } & \mathrm{m} \\ \text { you } & \text { pretty.2sg.f } & \text { upon } & \text { sister } & \text { of } & \text { you }\end{array}$

'You are prettier than you sister.'

(iv) Exceed Comparative from Duala (Ittmann 1939: 187, cited in Stassen 2013)

$\begin{array}{llllll}\text { nin } & \text { ndabo } & \text { e } & \text { kolo } & \text { buka } & \text { nine } \\ \text { this } & \text { house } & \text { it } & \text { big } & \text { exceed } & \text { that }\end{array}$

'This house is bigger than that.'

Of the four types of comparatives posited by Stassen, TID employs two distinct constructions to express comparison which are in parallel with Conjoined Comparatives and Locational Comparatives. In TID, of these two constructions, the "designated comparative constructions which express explicit orderings between two objects with respect to the degree or amount to which they possess some property" and which "are based on specialized morphology and syntax to express superiority, inferiority, and equality" (Kennedy 2006) is the Locational Comparative construction. Conjoined Comparatives are two juxtaposed clauses which express the ordering between the two objects not in terms of the degree or amount of the possessed property but in terms of two distinct predicates which are either semantic or syntactic opposites of each other. The Locational Comparative construction in TID, on the other hand, involves single predication in which the two participants of comparison, i.e. the standard and the comparee, occur in the same clause. Locational Comparatives are also distinguished by the use of a designated manual sign, which we represent as $\mathrm{IX}_{\mathrm{COMP}}{ }^{2}$ and the appropriate nonmanuals expressing degree of the compared property. Agreement and directionality of movement of the manual sign IX $\mathrm{X}_{\text {COMP }}$ play a crucial role in the formation of the Locational Comparative constructions of TID. Thus comparative constructions are part of the grammatical system of the language. Further, our findings also indicate that agreement in sign languages functions in areas other than verbal agreement as well.

The outline of the paper is as follows. In the Introduction, we present a brief survey of the basic properties of sign languages, give information about TID and state our research questions respectively. Section 2 presents the description of our methodology. A discussion of the properties of the comparative construction strategies and their semantic range in TID is presented in Section 3. Section 4 gives the description of the Conjoined Comparative construction. The description of Locational Comparatives is given in Section 5. Section 6 presents conclusions.

\subsection{Sign Languages}

Sign languages, like spoken languages, are natural languages of human communities; they are the linguistic systems used by the deaf members of the community. Sign languages are also the major means of communication of individuals with speech pathology. Although it is safe to assume that it is potentially possible for every speech community to have members who use sign language as

\footnotetext{
${ }^{2}$ The term "index of comparison" refers to the manual sign that is particular to the comparative constuction in Turkish Sign Language. The convenion in sign linguistics is to refer to such manual signs as "index". Therefore it is crucial that the reader is aware that the term "index of comparison" in this text is being used differently from Dixon's (2012) use of the term "index" in his typological works on comparative constructions.
} 
their native language so that there can be as many sign languages as there are spoken languages, the Ethnologue (2016) lists only 138 sign languages in contrast to 7,102 spoken languages. ${ }^{3}$

Human language is expressed in two modalities: the aural-oral modality and the visual-gestural modality (Meier 2012). Spoken languages use the aural-oral modality, sign languages the visualspatial modality. As visual-spatial languages, sign languages use hands and body and facial movements in the articulation of their meaningful units while spoken languages use the organs related to the sound system - the mouth, tongue, etc. - as articulators. Inherent in the modality difference between sign and spoken languages is also the difference between the perceptual systems involved in interpretation - spoken languages are perceived auditorily, sign languages visually.

Although the modality difference between sign and spoken languages gives rise to a number of differences in the manner in which the meaningful units are expressed in the respective languages, the grammars of sign languages as natural languages are composed of the same components as spoken languages; phonology, morphology, syntax, semantics, pragmatics. Modality differences manifested in the various components of the grammar of sign languages give rise to sign language typology.

Phonologically, the structure of sign languages as natural languages is based on the same linguistic principle of duality in expression as spoken languages (de Boer et al. 2012); sign languages, too, combine meaningless elements to form meaningful units. Spoken languages use sounds - consonants, vowels - to build the meaningful elements in their systems. As visual systems, sign languages use manual and nonmanual elements as their building blocks. The first description of the phonological system of American Sign Language (ASL) by Stokoe (1960) established the three main components of the manual signs as hand configuration, orientation and movement. Nonmanual signs involve movements of the upper part of the body and of the various parts of the head. Some of the nonmanuals common to sign languages are body lean/shift, shoulders thrust forward, head tilt/shake/nod, eye opening/gaze/squint, eyebrow raise/furrow/lowering, mouthing and mouth movements, puffed cheeks (Pfau and Quer 2012). Nonmanuals are the prosodic elements of sign languages that function at the lexical and syntactic levels.

A consequence of the modality difference between sign languages and spoken languages is the timing effect in the production of the building blocks. Spoken languages are sequential, while sign languages allow a higher degree of simultaneity in the production of their meaningful units (Sandler and Lillo-Martin 2006). Imposed by the physiological constraints of the aural-oral modality of spoken languages, the articulatory system of spoken languages operates linearly. Sequentiality is therefore an inherent property of the articulatory system of spoken languages, coarticulation being highly restricted in the oral modality. The distributed nature of the articulators, on the other hand, renders a higher degree of simultaneity in articulation for sign languages.

As visual linguistic systems, sign languages use space to locate signs produced manually and as such one of the parameters included in the lexical entry of a manual sign is its location in the signing space. The signing space is the physical space surrounding the signer where the signs are articulated. The phonologically distinctive spatial parameters are proximal, distal, and contact,

\footnotetext{
${ }^{3}$ The recognition of sign languages as linguistic systems on a par with spoken languages dates to 1760 when Abbé de L'Éppé founded the school for the deaf in Paris where he developed the methodology to be used in the education of the deaf. The dichotomy between the sign language approach to deaf education versus the oral approach initially advocated by Samuel Heinicke (1729-90) of Germany remained a source of much debate in the field until recent times. Presently, most educational systems opt for a holistic approach to the education of the deaf. The recognition of sign languages as formal systems by linguists, however, had to wait another two centuries until 1960 when Stokoe (1960) published the first analysis of American Sign Language. Sign linguistics has been gaining momentum since.
} 
where the location of a sign is defined with respect to the vertical and horizontal axis; the vertical axis is specified in relation to the torso, the horizontal axis relative to the side of the dominant hand.

Another aspect in which space is crucial in sign language is the expression of referentiality; discourse referents are located in the signing space by pointing to a location which represents their $\mathrm{R}$ (eferential)-locus in discourse. Referents thus located by the process of "nominal establishment" (Sandler and Lillo-Martin 2006) are identified in discourse manually by indexing (IX), i.e. using the index finger to point to the R-locus of the referent in the signing space, and/or nonmanually by body lean/shift, head tilt and/or eye gaze in the direction of the intended referent. As will be discussed in section 5 where we document the Locational Comparatives, nominal establishment also plays a crucial role in the expression of the comparative constructions in TID as reflected in the directionality of IX $\mathrm{XOMP}_{\mathrm{C}}$, an arc shaped movement of the hand from the R-locus of the standard to that of the comparee, which has a function similar to that of the standard marker in the comparative constructions in spoken languages.

Regarding part-of-speech categorization, sign languages share the principles of spoken languages (Meir 2012). Word classes are distinguished by morphological and syntactic properties in sign languages, too, although the manner and the degree to which these properties are manifested by the individual members of the class vary significantly from one sign language to another as well as from those of spoken languages. For instance, sign languages lack case marking on nouns. Noun inflection for number is relatively limited, modification of the noun by quantifiers or number lexemes being the more common means to express noun plurality in sign languages (Zwitserlood et al. 2013). Verbs are typically inflected for aspect, but not for tense (Rathmann 2005, Sandler and Lillo-Martin 2006, Dikyuva 2011). Although a sign language may possess a distinct tense lexeme, tense can also be marked by time adverbials (Neidle et al. 1998).

Verb subcategorization in sign languages differs significantly from that of spoken languages. In contrast to spoken languages in which verb subcategories are based on argument structure, in sign languages it is the presence versus absence of agreement inflection on the verb which is expressed by pointing in the signing space. Agreement determines class membership (Sandler and Lillo-Martin 2006). Verbs are typically subcategorized into three classes: plain, agreement, and spatial verbs. Agreement verbs are those that make use of points in the space to which referential value with respect to the participants in the discourse is ascribed. Single agreement verbs mark agreement only with the object, double agreement verbs mark agreement with both the subject and the object. In a double agreement verb, agreement is marked by the movement and the path of the hand in the referential space from the locus of the subject to that of the object. The class of "backward" agreement verbs encode agreement in the reverse direction, i.e. from the location of the object to that of the subject. Spatial verbs differ from agreement verbs in that their starting point is the location of the beginning of movement rather than that of the subject. Thus verb categorization in sign languages does not necessarily map onto the argument structure of the individual predicates. Table 1 reflects the verb classes and some members of the individual classes in TID where subscripts on agreement verbs indicate the arguments the verbs agree with (cf. Sevinç 2006). ${ }^{4}$

\footnotetext{
${ }^{4}$ Throughout the text, the TID examples are given in capital letters in conformity with the convention of the written representation of sign language data.
} 


\begin{tabular}{|l|l|}
\hline Verb Category & TID verbs \\
\hline Plain verbs & SLEEP, LOVE \\
\hline Agreement verbs & SEE $_{\mathrm{b}}$ \\
Single agreement & ${ }_{\mathrm{a}}$ GIVE $_{\mathrm{c}}$ \\
Double agreement & ${ }_{\mathrm{b} E C E I V E}$ \\
\hline Backward agreement & WALK $^{\mathrm{a}}$ \\
\hline Spatial verbs &
\end{tabular}

Table 1. Verb categories in TİD

Parallel to many spoken languages, adjectives can function as predicates and as modifiers of nouns in sign languages. As noun modifiers, adjectives can precede or follow the head noun in TID (Nuhbalaoğlu and Özsoy 2014). As a word class, TID adjectives are distinguished from verbs in the absence of aspect inflection; in clauses with adjectival predicates, perfectivity is expressed through time adverbials. As will be discussed in the following sections, adjectives are also distinguished from verbs by their syntactic distribution. Additonally, TİD adjectives (but not verbs) can function as predicates in the Locational Comparative construction.

Another distinctive feature of the morphology of sign languages is that most sign languages have a class of morphemes generally labelled as "classifiers" (CL) which are handshapes that represent the semantic or physical properties of entities they denote (Pfau and Steinbach 2011). The three main types of classifiers are (i) shape (ii) size and (iii) handling classifiers. Classifiers can also be incorporated into some verbs where the handshape of the verb undergoes change to indicate the nature of its argument.

Syntactically, TID has no copula. A clause with a nonverbal predicate is realized as the subject and the predicate. The subject can be a full NP or can be indexed by the use of IX which indicates the R-locus of the referent or nonmanually by body lean/shift in the direction of the R-locus of the subject.

\subsection{Turkish Sign Language}

Turkish Sign Language (TID) is the native language of the deaf in Turkey. The present estimate of the deaf population in Turkey is 80,000 of whom 60,000 report TiD to be their native language (Kemaloğlu and Kemaloğlu 2012). Turkish Sign Language is the oldest reported sign language in the literature (cf. Miles 2000); sources indicate that a sign language was in use in the royal court of the Ottoman Empire in the $16^{\text {th }}$ century, even by speakers. Nevertheless, whether the sign language used in the royal court is historically related to the TID of today is at best questionable.

\subsection{Research Questions}

We formulated our research questions as follows:

a. What are the ways in which TiD expresses comparison?

b. Does TID have a "designated" comparative construction? If yes, what are its properties?

c. Do these properties differ from those of the comparative constructions of spoken languages? If yes, how?

d. Do these properties share any features that are observed in other constructions of TID? 
e. Regarding the sign language specific elements of the comparative construction in TID, what is their significance for the grammar of sign languages and/or for the typology of comparative constructions?

\section{Methodology}

The data analyzed in this study were elicited from a total of 7 fluent deaf signers of TID ( 3 male and 4 female). At the time of recording the informants were aged between 19 and 55 years. All of the informants attended schools for the Deaf. Their educational levels range from primary school to university. They all reside in Istanbul and are presently actively involved in the Deaf community.

In the data elicitation sessions, the signers sat facing each other and interacted. The interpreter pre-recorded the instruction videos of the elicitation tasks and monitored the recording sessions. The stimuli were presented on a computer located on a small table positioned between the two signers or directly in front of the signer in the case of individual tasks. For the present study we have made use of three HD camcorders, ${ }^{5}$ two capturing the frontal views of the signers, and the third camera capturing the side views of both of the signers. All of the recordings took place at the linguistics laboratory of Boğaziçi University. The total length of footage recorded for the purposes of this study is approximately 6.5 hours. $^{6}$

Data elicitation tasks were prepared to elicit (semi-)natural data. Different pictures that induce comparison and/or description were used to elicit data. These are exemplified in Example 1 and Example 2 below which respectively aimed at eliciting comparison of size and comparison of degree of emotion. The analysis of the data elicited through the tasks also revealed that while adjectival predicates freely occur in both Conjoined and Locational Comparative constructions, verbal predicates are restricted to the Conjoined construction.

Example 1: Data elicitation task for a comparative construction with an adjectival predicate

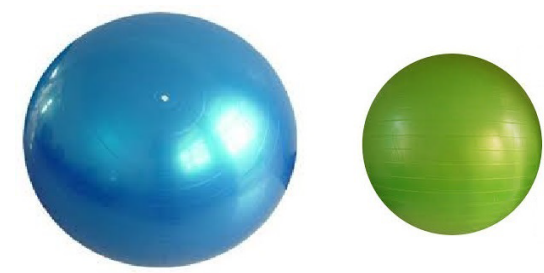

Intended elicitation: 'THE BLUE BALL IS BIGGER THAN THE GREEN ONE.’

\footnotetext{
${ }^{5}$ Sony HDR-PJ10, recording resolution display 1920x1080i.

${ }^{6}$ The video data used in the present study were edited via Adobe CS5 Premiere Pro and Adobe Media Encoder and transcribed/annotated by an interpreter of the TÜBİTAK project $111 \mathrm{~K} 314$.
} 
Example 2: Data elicitation task for a subject comparative construction with a verbal predicate

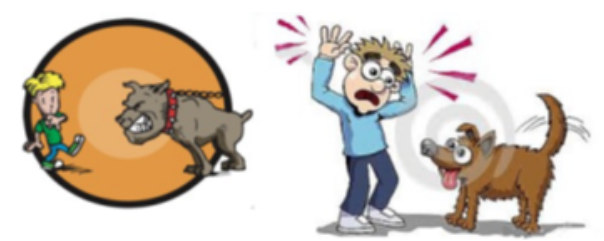

Intended elicitation: 'THE MAN IS MORE AFRAID OF THE DOG THAN THE BOY.'

\section{Comparatives and Comparison}

Comparison is "a mental act where two objects are assigned a position on a predicative scale" (Stassen 2006: 686); linguistically, the mental act is realized by means of the encoding of the elements in a comparative construction. Syntactically, TiD employs two distinct comparative constructions to express comparison, for which we follow Stassen's (2013) classification: Conjoined Comparatives and Locational Comparatives. Since Locational Comparatives can express gradation of adjectives, we hold that it is this construction which functions as the "designated" comparative construction in TID. The Conjoined Comparative construction differs from the former in that it involves two independent juxtaposed clauses with parallel structures in which verbs as well as adjectives can function as predicates.

TID encodes the semantic range of the comparative constructions from scalar to absolute comparison by different syntactic strategies. We define scalar gradability as the possession of a property by one of the objects to a more, less or equal degree relative to the other (Sapir 1944, Dixon 2012, Stassen 2013) and absolute gradability as the possession of a property by one of the participants of comparison as opposed to the absence of that property in the other participant. In TID, absolute gradability is expressed by the Conjoined Comparative construction, while scalar gradability of adjectival predicates is expressed by the Locational Comparative construction.

With respect to the comparative construction in TID, what is significant is that in both the Conjoined Comparative construction and the Locational Comparative construction the two participants of comparison are introduced as the "topics of comparison". The phrase introducing the topics of comparison, which we label the "topic phrase", precedes the predication of comparison. The participants are located in the opposite sides of the signing space, i.e. ipsilaterally and contralaterally, representing their respective R-locus in the comparative predication.

TID uses both manual and nonmanual means of articulation to encode the different aspects of the structural and semantic properties of the comparative construction in the sign language modality as described below.

\section{Conjoined Comparatives}

The Conjoined Comparatives in TID are biclausal constructions that involve two juxtaposed clauses with parallel structures, where the predicates of the respective clauses are either adjectives or verbs and where the arguments of the respective predicates are interpreted as the standard of comparison and the comparee. In adjectival (and verbal subject) comparative constructions, the standard and the comparee are always NPs that function as the subjects of their respective clauses; the subject of the first clause is the standard and that of the second clause is the comparee. In object verbal comparative constructions, on the other hand, what are compared are the two objects. These constructions are discussed in detail in Sections 4.1 and 4.2 respectively. 
The nature of the predicates of the two juxtaposed clauses determines the semantics of the comparative constructions. Constructions with adjectival predicates express absolute gradability, i.e. the comparee does not possess the property possessed by the standard. Absolute gradability is encoded by three distinct patterns of predication:

(i) the predicate of the second clause is the antonym of the predicate of the first clause,

(ii) the predicate of the second clause is the negated form of the predicate of the first clause,

(iii) a combination of (ii) and (i), where the second clause contains both the negated form of the predicate of the first clause as well as its antonym.

The constructions with verbal predicates, on the other hand, encode scalar gradability by the use of the degree sign MORE/LESS. To determine the nature of gradability of comparison in verbal comparative constructions, the data were restricted to psychological predicates which express a change in the psychological state of an experiencer (Belletti and Rizzi 1988).

\subsection{Adjectival Predicates}

With respect to constructions with adjectival predicates, the predicates in the conjoined structure can be antonymous parameters, negated parameters, or a combination of the two. The syntactic structures of these predications are as follows:

\section{(i) Adjectival Antonymous Predicates}

The two participants of the comparison are compared with respect to two different parameters where these two parameters are antonymous, as in example (5). This type of comparison is summarized in Construction 1.

Construction 1: [NP NUM N] [CL $\left.\mathrm{CLJ}_{1}\right]\left[\mathrm{CL}_{\mathrm{b}} \mathrm{ADJ}_{2}\right]$

\begin{tabular}{|c|c|c|}
\hline $\begin{array}{l}\text { [TWO } \\
\text { two }\end{array}$ & $\begin{array}{l}\text { MEN] } \\
\text { men }\end{array}$ & $\begin{array}{l}\text { [ONE } \\
\text { one man }\end{array}$ \\
\hline
\end{tabular}

'(There are) two men. One is tall. One is short.'

Semantically, antonymous predication expresses that the subject of the second clause possesses the property opposite to that possessed by the subject of the first clause, thus inferring that the former does not possess the property of the subject of the first clause at all.

\section{(ii) Adjectival Negated Predicates}

In the negated construction illustrated in example (6), the same parameter occurs as the predicate of the two clauses; however, the parameter in the first clause is negated in the second clause by the lexical sign NOT. This type of comparison is shown in Construction 2.

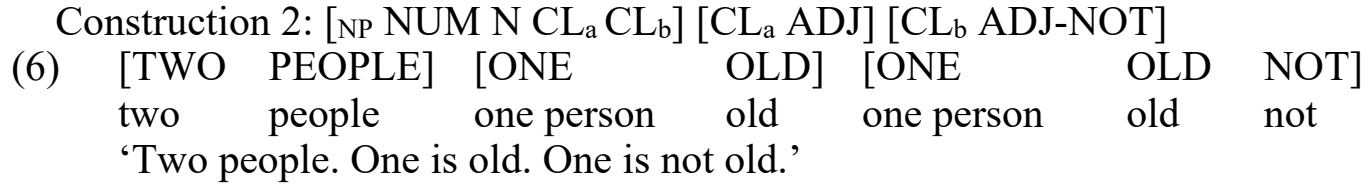

Regarding the semantics of comparison, negated predication ascertains that the subject of the second clause does not possess the property possessed by the subject of the first clause; the possession of the opposite property is inferred. 


\section{(iii) Combined Construction}

In the combined construction, the first clause after the topic phrase introduces the standard and the parameter. The second clause has the comparee as the subject, negates the parameter, and is followed by the antonym of the parameter in a third clause, as in (7). The comparee can be expressed manually by indexing (IX) and/or nonmanually by body shift (bs). This type of comparison is expressed by Construction 3.

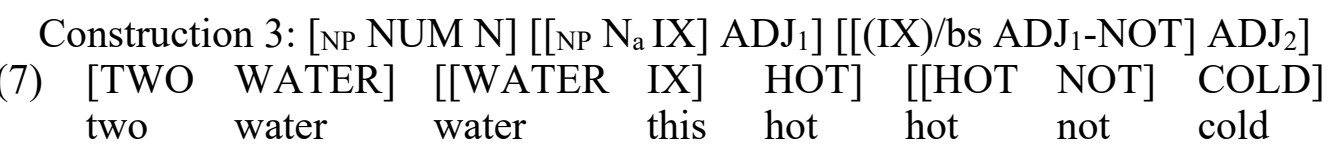

'(There are) two (glasses of) water. This water is hot. (This water) is not hot. (It is) cold.'

The combined construction expresses both the possession of a specific property by the subject of the first clause while negating its possession by the subject of the second clause. The construction also affirms that the subject of the second clause possesses a property which is opposite to the one possessed by the subject of the first clause.

Thus it is possible to express the comparison of the possession of a property by two entities in three different ways in the Adjectival Conjoined Comparative construction.

\subsection{Verbal Predicates}

With respect to the comparison of verbal predicates, the elicitation task focused on psychological predicates in order to elicit gradability in predication. The comparison expresses the degree of intensification of the state denoted by the psychological predicate. When a verb functions as the parameter of comparison, either two different subjects are being compared with respect to a single object or two different objects are being compared with respect to a single subject. The following are the properties of elements in a comparative construction with a verbal predicate:

- The standard is on the contralateral side of the body, located by indexing and/or body shift/head shift.

- The comparee is on the ipsilateral side of the body, located by indexing and/or body shift/head shift.

- The parameter marker occurs in the clause that contains the comparee, i.e. the sign MORE is articulated in the second clause before the parameter.

The comparison of subjects is formalized in Construction 4. The comparison of objects is illustrated in Construction 5.

Construction 4: $\left[\mathrm{NP}_{\mathrm{a}} \mathrm{NP}_{\mathrm{b}} \mathrm{V}\right]\left[\mathrm{NP}_{\mathrm{c}} \mathrm{NP}_{\mathrm{b}} \mathrm{MORE} \mathrm{V}\right]$

$\begin{array}{lllllll}{[\text { GIRL }} & \text { DOG } & \text { SCARED }] & {[\text { MAN }} & \text { DOG } & \text { MORE } & \text { SCARED] } \\ \text { girl } & \text { dog } & \text { scared } & \text { man } & \text { dog } & \text { more } & \text { scared }\end{array}$

'The girl is scared of the dog. The man is more scared of the dog.' 
Construction 5: $\left[\mathrm{NP}_{\mathrm{a}} \mathrm{NP}_{\mathrm{b}} \mathrm{V}_{\mathrm{b}}\right][e \text { bs V}]^{7}\left[e \mathrm{NP}_{\mathrm{c}} \mathrm{V}_{\mathrm{c}}\right]$ [e bs MORE V] $]^{8}$

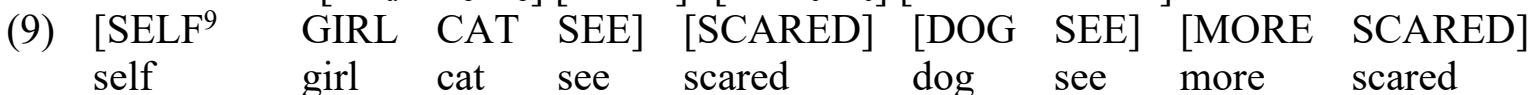

'The girl sees the cat and is scared. (She) sees the dog and is more scared.'

\subsection{Order in Conjoined Comparatives}

Various constituent orders possible in the Conjoined Comparative construction in TID are summarized in Table 2.

\begin{tabular}{|c|c|c|c|}
\hline Construction & Topic phrase & Clause(s) with standard & Clause(s) with comparee \\
\hline 1 & [NP NUM N] & {$\left[\mathrm{CL}_{\mathrm{a}} \mathrm{ADJ}_{1}\right]$} & {$\left[\mathrm{CL}_{\mathrm{b}} \mathrm{ADJ}_{2}\right]$} \\
\hline 2 & {$\left[\mathrm{NP} N U M N \mathrm{CL}_{\mathrm{a}} \mathrm{CL}_{\mathrm{b}}\right]$} & {$\left[\mathrm{CL}_{\mathrm{a}} \mathrm{ADJ}\right]$} & [CL $\mathrm{CL}_{\mathrm{b}}$ ADJ-NOT] \\
\hline 3 & [NP NUM N] & {$\left[\left[\mathrm{NP}_{\mathrm{a}} \mathrm{IX}\right] \mathrm{ADJ}_{1}\right]$} & {$\left[\left[(\mathrm{IX}) / \mathrm{bs} \mathrm{ADJ}_{1}-\mathrm{NOT}\right] \mathrm{ADJ}_{2}\right]$} \\
\hline 4 & & {$\left[\mathrm{NP}_{\mathrm{a}} \mathrm{NP}_{\mathrm{b}} \mathrm{V}\right]$} & {$\left[\mathrm{NP}_{\mathrm{c}} \mathrm{NP}_{\mathrm{b}}\right.$ MORE V] } \\
\hline 5 & & {$\left[\mathrm{NP}_{\mathrm{a}} \mathrm{NP}_{\mathrm{b}} \mathrm{V}_{\mathrm{b}}\right][e$ bs V] } & {$\left[e \mathrm{NP}_{\mathrm{c}} \mathrm{V}_{\mathrm{c}}\right][e$ bs MORE V] } \\
\hline
\end{tabular}

Table 2. Order of constituents in Conjoined Comparatives

The order of elements in a Conjoined Comparative construction is as follows: (i) an optional topic phrase introducing the participants in the comparative construction, (ii) the clause containing the standard, (iii) the clause containing the comparee.

\section{Locational Comparatives}

The Locational Comparative construction is the "designated" comparative construction of TiD that expresses scalar gradability of adjectival predicates. It is distinguished from the Conjoined Comparatives by the presence of a single adjectival predicate (parameter of comparison) expressing the property shared by the standard and the comparee and the use of a special kind of index which we label as IX $\mathrm{X}_{\mathrm{COMP}}$ (index of comparison) to express the relation between the two NPs.

The Locational Comparative construction consists of: (i) an optional topic phrase which specifies the participants to be compared, (ii) the localization of the two participants in the signing space by indexing or body shift, and (iii) the predication of comparison. In the absence of an overt topic phrase, localization also introduces the participants of comparison, thus functioning as topic phrase.

\subsection{Participants in Locational Comparatives}

The participants are located on the opposite ends of the signing space by indexing. The standard is located contralaterally, i.e. on the side opposite the dominant hand, and the comparee ipsilaterally, i.e. on the side of the dominant hand. Even in the absence of the expression of the standard, the ipsilateral side represents the location of the comparee.

\footnotetext{
${ }^{7} e$ is the (generative) convention for representing unpronounced constituents.

${ }^{8}$ See is a single agreement verb in TID, therefore it agrees with the object. Scare is a non-agreeing verb.

${ }^{9}$ SELF has similar functions as emphatic reflexive markers in spoken languages.
} 


\subsection{IX}

TID uses a special kind of index in comparative constructions - IX $\mathrm{COMP}_{\mathrm{C}}$ - the Comparative Index. IX $\mathrm{COMP}_{\mathrm{C}}$ has three phases:

(i) indexing of the standard,

(ii) arc movement from the R-locus of the standard to the R-locus of the comparee,

(iii) indexing of the comparee.

The phases of IX

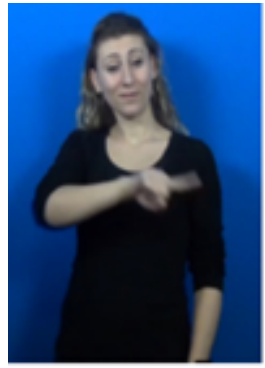

Phase 1: IX Standard

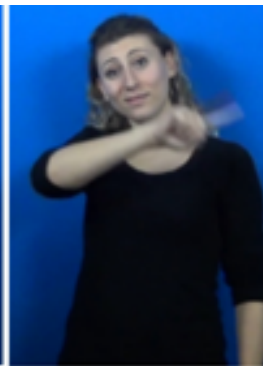

10

Phase 2:

Arch Movement

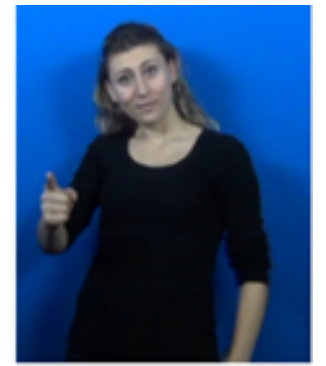

Phase 3:

IX Comparee

Figure 1. Phases of the Comparative Index IX

Locating the standard and the comparee in the opposite ends of the signing space to establish the respective referentiality of the two participants of comparison is done by means of indexing, and/or body shift in the direction of the intended location. The movement of the hand in IX $\mathrm{COMP}_{\mathrm{C}}$ is coarticulated with eye-gaze shift from the R-locus of the standard to that of the comparee. During this phase, the eye gaze is constant throughout the arch movement of the hand. The manual sign expressing the predicate (parameter) is formed at the location of the comparee. Thus TID uses both manual and nonmanual means of articulation to encode the different aspects of the structural and semantic properties of the comparative construction in the sign language modality.

\subsection{Gradability and Degree Signs}

The expression of gradability in TID exhibits allomorphic variation. There are two variants of the Locational Comparative construction and their distribution is determined by the nature of the predicate. TID has lexical degree signs (parameter markers) MORE, MOST, and LESS to express superiority (relative and absolute) and inferiority (relative but not absolute). The signs are coarticulated with nonmanuals associated with the respective degree of comparison. Syntactically, both lexical signs MORE and LESS precede the predicate. The second means in which gradability is encoded in TID is by the incorporation of the degree into the predicate sign, i.e. the sign of the parameter.

\section{(i) Lexical Gradation}

TID marks degrees of gradability - comparative MORE, superlative MOST and inferiority LESS - with distinct manual signs which can occur optionally in the comparative construction. MORE 
is articulated by the selection of all fingers of the dominant hand and a twist of the wrist coarticulated with nonmanuals. Phonologically, MORE is produced with the selected fingers of the dominant hand, slightly spread and slightly curved which remain so throughout the movement. The nonmanuals coarticulated with the lexical sign MORE are eye opening and eyebrow raise. The manual signs for comparative MORE, superlative MOST and LESS are illustrated in Figure 2, Figure 3, and Figure 4 respectively. ${ }^{10}$

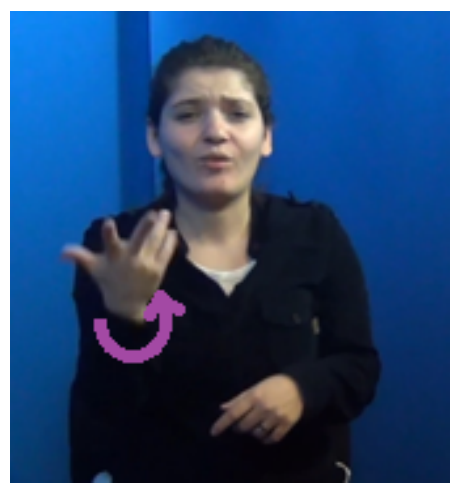

Figure 2. MORE

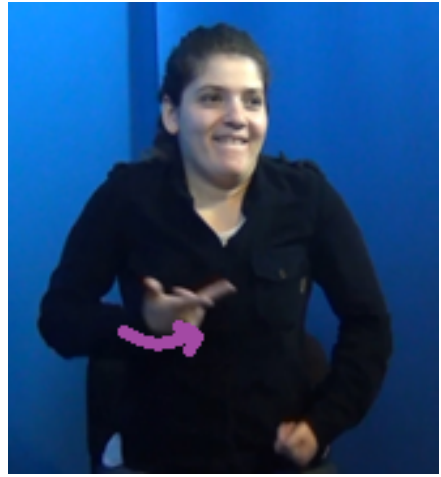

Figure 3. MOST

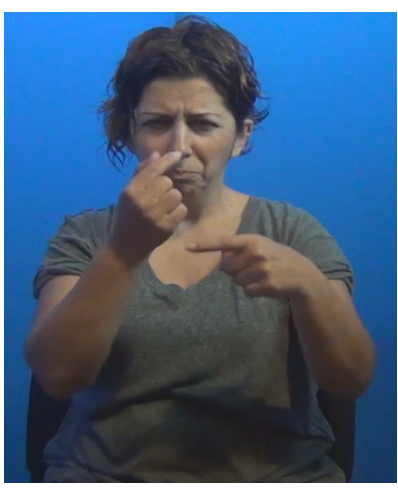

Figure 4. LESS

The sign MOST is articulated with index and middle fingers selected, with the thumb extended and the aperture between the selected fingers open and the unselected fingers closed, as opposed to the MORE sign where all the fingers are selected and aperture is open. For both signs the orientation is palm up. ${ }^{11}$ The sign LESS is articulated with the extended index finger making a narrow opening with thumb as in Figure (4). ${ }^{12}$ All three degree signs are coarticulated with their respective nonmanuals described in (iii) below.

In the case of gradable predicates, the expression of the comparative form of the manual sign of the degree is morphologically conditioned, some variants exhibiting incorporation or cliticization of the degree particle into the predicate. In these latter types of constructions, the sign for MORE semantically combines with the sign of the parameter. The incorporation of the manual sign for MORE seems to be conditioned by the articulatory properties of the manual sign. When overtly present, the sign always precedes the predicate. When not present, it is incorporated into the parameter.

\section{(ii) Incorporation}

We hold that the incorporation of the degree into the predicate sign behaves in a manner similar to the affixation of the comparative -er to adjectives in English. Figure 5(a-b) illustrate the incorporation of MORE into the predicate BIG, whose articulation involves the two hands with open and extended fingers, where the hands are held apart from each other in neutral space in the front of the torso. In (5b), which represents the incorporated comparative degree BIGGER, the two

\footnotetext{
${ }^{10}$ Due to space limitations, we confine our discussion of gradability to the properties of comparative constructions and restrict the discussion on superlatives and inferiority to the description of the manual signs MOST and LESS.

${ }^{11}$ We leave the discussion on the nonmanual properties of superiority, including the shoulder movement observed in Figure 3, for a later discussion on the superlative construction in TID.

${ }^{12}$ The sign LESS in Figure 4 is articulated with the dominant hand. The passive hand is articulating the participant.
} 
hands are further apart and the eyes are wider open and eyebrows are further raised. ${ }^{13}$

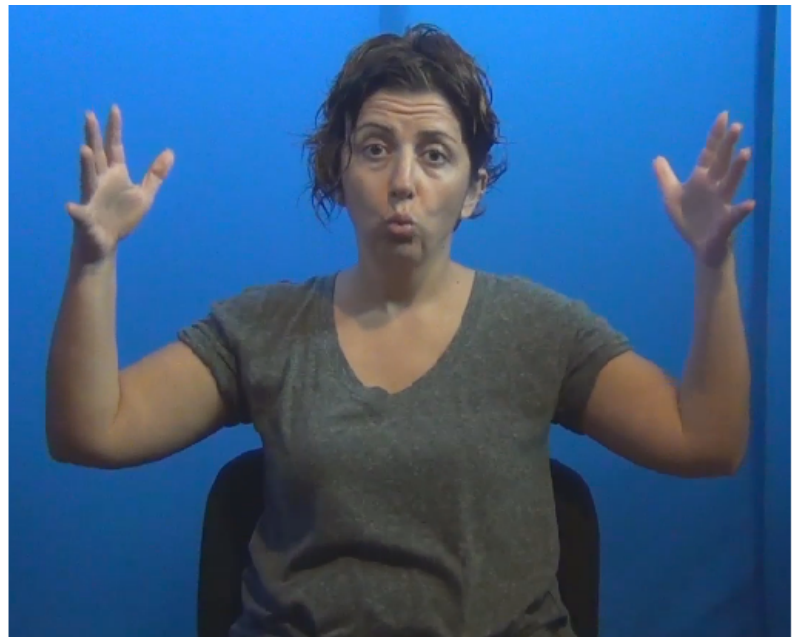

Figure 5(a). BIG

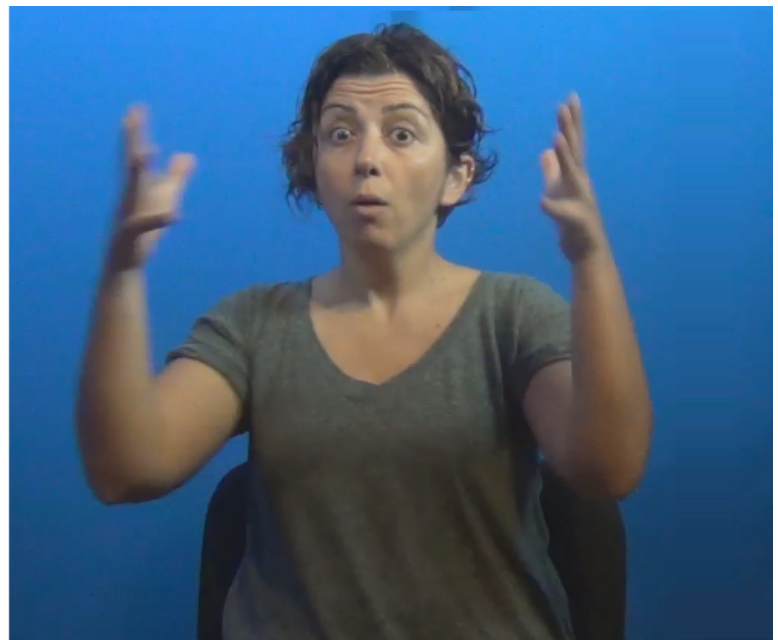

Figure 5(b). BIGGER

The incorporation of MORE into the predicate THIN the articulation of which reflects its semantic opposition to a predicate like BIG is illustrated in Figure 6(a-b). THIN is articulated with the selection of the thumb and the little finger of the two hands extended where the unselected fingers are closed and the hands are held close to each other in neutral space in the front of the torso. The incorporation of the degree into the predicate THIN involves crossing the two hands even further with the eyes squinted and eyebrows furrowed.

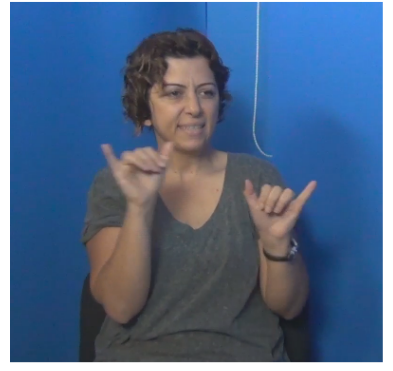

Figure 6(a). THIN

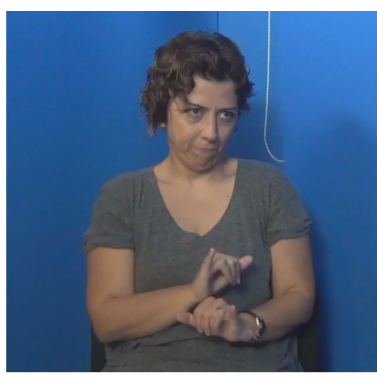

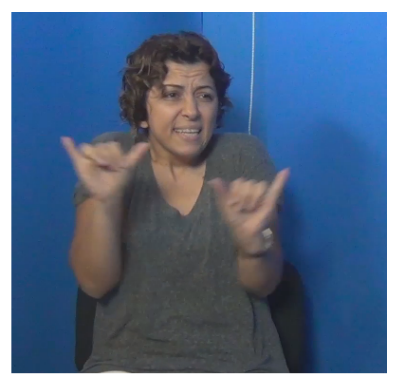

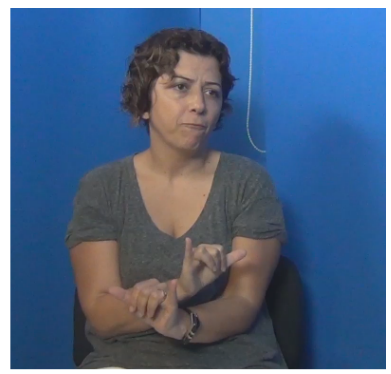

Figure 6(b). THINNER

If the degree sign MORE is overtly present in the construction, it immediately precedes the parameter, i.e. the predicate. Example (10), in which both IX $\mathrm{X}_{\mathrm{COMP}}$ and degree sign MORE are overtly present, illustrates a typical example for this type of comparison in TỉD.

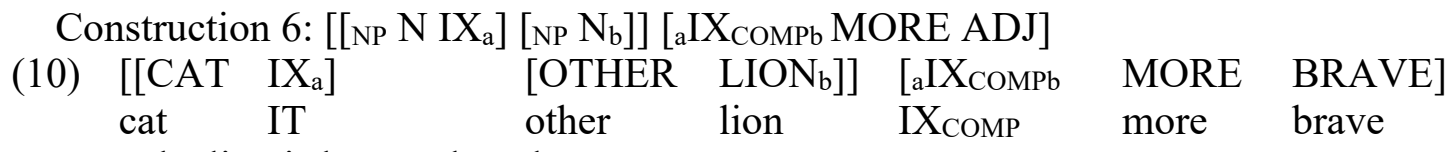

Example (11) illustrates incorporation of the degree sign MORE into the IX $\mathrm{X}_{\mathrm{COMP}}$ sign. The incorporation is indicated nonmanually by eye-opening (eo) and eyebrow raise (ebr).

\footnotetext{
${ }^{13}$ The apparent inverse distance between the hands in Figure 5(a) and 5(b) is due to the fact that 5(a) illustrates the sign BIG in isolation while 5(b) is the sign articulated in the comparative construction. The difference reflects the effect of the use of space in producing manual signs in isolation and in constructions.
} 
Construction 7: [[NP N IX $\mathrm{a}_{\mathrm{a}}$ [NP N IX $\left.\mathrm{b}\right]$ [a $\left.\mathrm{I} \mathrm{X}_{\mathrm{COMPb}} \mathrm{ADJ}\right]$ (11)

\begin{tabular}{|c|c|c|c|c|c|}
\hline \multirow{3}{*}{$\begin{array}{l}\text { [[JALE } \\
\text { Jale }\end{array}$} & \multirow{3}{*}{$\begin{array}{l}{\left[X_{\mathrm{a}}\right]} \\
\text { SHE }\end{array}$} & & & \multicolumn{2}{|l|}{ - eo } \\
\hline & & DERYA $_{b}$ & IX & $\overline{\mathrm{C}_{\mathrm{a}} \mathrm{IX} \mathrm{X}_{\mathrm{COMPb}}}$ & STUBBORN] \\
\hline & & Derya & SHE & IX & stubborn \\
\hline
\end{tabular}

The degree sign MORE and $\mathrm{IX}_{\mathrm{COMP}}$ can be incorporated into the sign denoting the parameter. As illustrated in example (12), some constructions involve morphophonological fusion of the degree sign MORE as well as of the index of comparison IX $\mathrm{X}_{\text {COMP }}$ into the parameter, where the fusion involves both a manual and spatial modification of the parameter sign.

Construction 8: [[NP NUM N]] [ADJ IX $\mathrm{a}_{\mathrm{a}}$ [ADJ $\mathrm{AD}_{\mathrm{b}}$ [aAJ $\left._{\mathrm{b}}\right]$

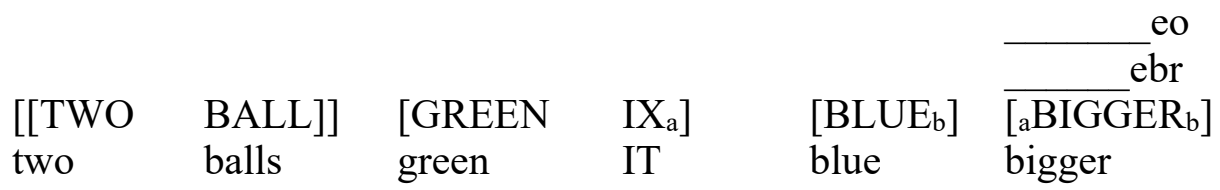

'Two balls. The blue is bigger than the green.'

The incorporation of the degree sign MORE into the adjectival predicate BIG is expressed manually by widening the distance between the two hands, which is co-articulated nonmanually with eye-opening and eyebrow raise. IX $\mathrm{X}_{\mathrm{COMP}}$ is incorporated into the predicate $\mathrm{BIG}$ by means of the movement of the hands from the R-locus of the standard to the R-locus of the comparee while forming the sign BIG.

\section{(iii) Nonmanuals}

The nonmanuals used to express gradability in comparative constructions are eye opening and eyebrow shape. The nonmanual for expressing higher degree of a positive value of a property is open eyes and raised brows. The higher degree of a negative value of a property is expressed by squinting eyes and furrowed brows.

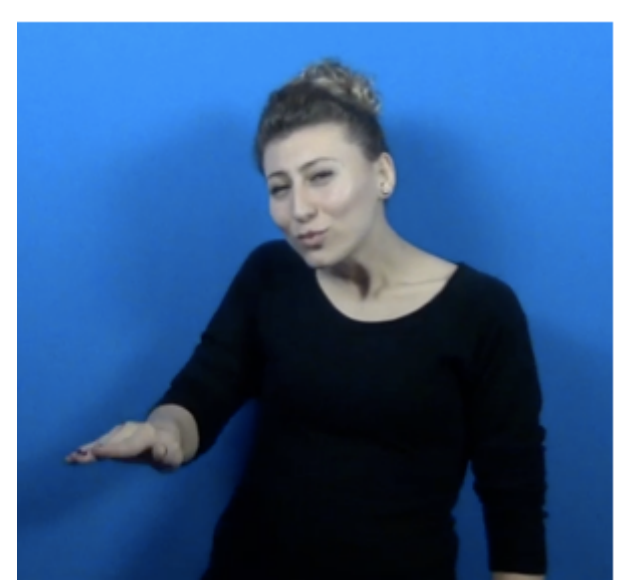

SMALL

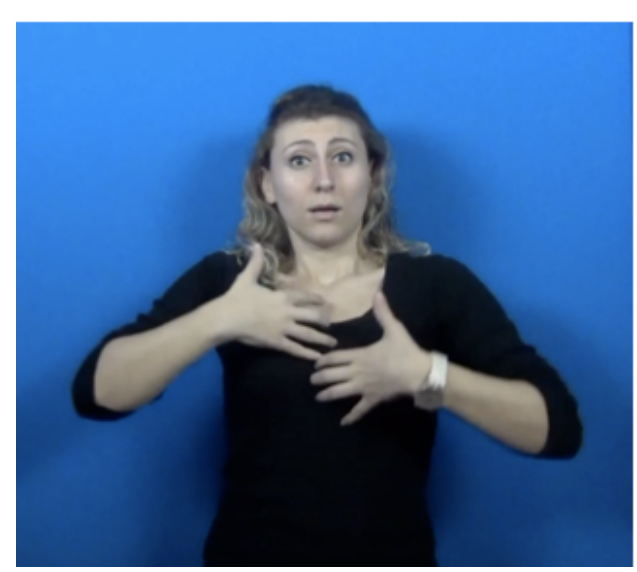

BRAVE

Figure 7(a). Higher degree of a negative value Figure 7(b). Higher degree of a positive value 


\subsection{Order of Constituents}

With respect to the order of constituents in a Locational Comparative construction, the two arguments are located on the opposite sides of the signing space, with the standard being located on the contralateral side and the comparee on the ipsilateral side. The standard precedes the comparee in a Locational Comparative construction. Any change in the order of the constituents leads to ungrammaticality. The standard can also be optionally omitted in a Locational Comparative construction. Example (13) illustrates such a case where the degree and IX COMP $_{\text {are }}$ incorporated into the adjective. The standard is not overtly expressed but is implicit in the topic phrase TWO BALL, which establishes the nature of the two objects being compared.

Construction 9: [NP NUM N] [[NP $\left.\left.e \mathrm{ADJ}_{\mathrm{b}}\right]_{\mathrm{a}} \mathrm{ADJ}_{\mathrm{b}}\right]$

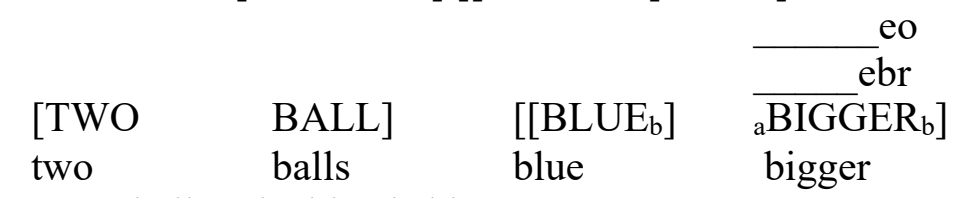

'Two balls. The blue is bigger.'

\begin{tabular}{|c|c|c|c|c|c|c|c|c|c|}
\hline 1 & & [[STD & $\left.\left(\mathrm{IX}_{\mathrm{STD}}\right)_{\mathrm{a}}\right]$ & [CPR & $\left.\left[X_{\mathrm{CPRb}}\right]\right]$ & ${ }_{\mathrm{a}} \mathrm{IX}_{\mathrm{COMPb}}$ & (MORE) & Predicate & (CPR) \\
\hline 2 & & [[STD & $\left.\left(\mathrm{IX}_{\mathrm{STD}}\right)_{\mathrm{a}}\right]$ & [CPR & $\left.\left[X_{\mathrm{CPRb}}\right]\right]$ & - & (MORE) & ${ }_{\mathrm{a}}$ Predicate ${ }_{\mathrm{b}}$ & \\
\hline 3 & & {$[$ [STD } & $\begin{array}{l}\text { body shift } \\
\text { to STD] }\end{array}$ & [CPR & $\begin{array}{l}\text { body shift } \\
\text { to CPR]] }\end{array}$ & ${ }_{\mathrm{a}} \mathrm{IX}_{\mathrm{COMPb}}$ & (MORE) & Predicate & (CPR) \\
\hline 4 & & {$[$ [STD } & $\left.\left(\mathrm{IX}_{\mathrm{STD}}\right)_{\mathrm{a}}\right]$ & {$\left[\mathrm{IX}_{\mathrm{CPRb}}\right.$} & CPR]] & ${ }_{\mathrm{a}} \mathrm{IX}_{\mathrm{COMPb}}$ & (MORE) & Predicate & \\
\hline 5 & [Topic] & [STD & $\left.\left(\mathrm{IX}_{\mathrm{STD}}\right)_{\mathrm{a}}\right]$ & [CPR & $\mathrm{IX}_{\mathrm{CPRb}}$ & {$\left[{ }_{\mathrm{a}} \mathrm{I} \mathrm{X}_{\mathrm{COMPb}}\right.$} & (MORE) & Predicate] & \\
\hline
\end{tabular}

Table 3. Order of constituents in TID Locational Comparative constructions (STD = standard, CPR = comparee)

The order of constituents in the Locational Comparative construction is consistent with the order of constituents in a non-comparative sentence in TID. Sevinç \& Bozşahin (2006) state that TİD is verb-final, and our findings are parallel to theirs in that the predicate is in final position in the Locational Comparative construction. As the constituent orders 1 and 3 in Table 3 illustrate, the comparee can optionally follow the predicate. Its function is left for further investigation.

Given that indexing toward an arbitrary location in space associates that locus with the R-locus of the NP, verbal agreement is expressed through this locus in sign languages (Sevinç \& Bozşahin 2006). Agreement in a Locational Comparative construction in TID is marked by the directionality either of the sign IX $\mathrm{X}_{\mathrm{COMP}}$ or of the predicate sign in the case of incorporation of $\mathrm{IX}_{\mathrm{COMP}}$. The directionality and body shift in the formation of IX in TID parallels backward agreement of the verbal paradigm. In the Locational Comparative constructions in TID, the comparee is expressed by an index pointing to its R-locus in the signing space or by body shift in the direction of the R-locus of the comparee, as described above. The indexing for the standard is optional, as mentioned above. In the absence of body shift, indexing of the comparee is obligatory. The directionality of indexing and body shift in the Locational Comparative construction is therefore similar to that of verbal agreement.

\section{Conclusion}

This paper has presented the description of the comparative constructions in a sign language. Turkish Sign Language (TID) has two comparative constructions, which are labeled as Conjoined Comparatives and Locational Comparatives in line with the classification of comparatives proposed by Stassen (2013). The paper provides a detailed description of the manual and 
nonmanual properties of the two comparative constructions. It is shown that TiD encodes the semantic range of the comparative constructions from scalar to absolute comparison by different syntactic strategies. Locational Comparatives are argued to be the designated comparative construction for TiD expressing scalar gradability of adjectival predicates. Locational Comparatives involve single predication where the standard and comparee are localized in the signing space by indexing or body shift. An arc movement from the locus of the standard to the locus of the comparee ends with the sign expressing the predicate. The Conjoined Comparative construction, on the other hand, involves two independent juxtaposed clauses with parallel structures in which verbs as well as adjectives can function as predicates. In both the Conjoined Comparative construction and the Locational Comparative construction the two participants of comparison are introduced as the "topics of comparison" by a topic phrase, which precedes the predication of comparison.

The paper also points out the similarities between the verbal agreement system and the Locational Comparative construction in TID. Our study reveals that a phenomenon similar to backward agreement, which is typically associated with the verbal agreement system of sign languages, also occurs in the comparative construction of TiD. This indicates that backward agreement is not restricted to the verbal system only. In the absence of body shift in Locational Comparatives, the comparee is always followed by an index pointing to its location in the signing space. The indexing after the standard is optional. These show that like verbal agreement, there is indexing of the NPs in the signing space that has the potential to be used in agreement.

\section{References}

Aronoff, Mark, Irit Meir, and Wendy Sandler. 2005. The paradox of sign language morphology. Language 81(2): 301-344.

Belletti, Adriana and Luigi Rizzi. 1988. Psych-verbs and theta-theory. Natural Language \& Linguistic Theory 6: 291-352.

de Beour, Bart, Wendy Sandler, and Simon Kirby. 2012. New perspectives on duality of patterning: Introduction to the special issue. Language and Cognition 4(4): 251-259.

Dikyuva, Hasan. 2011. Aspectual non-manual expressions in Turkish Sign Language (TID). Unpublished MA Thesis. University of Central Lancashire: Preston, UK.

Dixon, Robert M.W. 2012. Basic Linguistic Theory: Further Grammatical Topics. Vol III. Oxford: Oxford University Press.

Lewis, M. Paul, Gary F. Simons, and Charles D. Fennig. (eds.) 2016. Ethnologue: Languages of the World. Edited by R. G. Gordon. $19^{\text {th }}$ ed. Dallas, Texas: SIL International. www.sil.org/resources/publications/entry/6133

Kemaloğlu, Yusuf and Pınar Kemaloğlu. 2012. The history of sign language and deaf education in Turkey. Kulak Burun Boğaz İhtisas Dergisi 22(2): 65-76.

Kennedy, Chris. 2006. Comparatives, Semantics. In: Allen, Keith (ed.). Encyclopedia of Language and Linguistics, $2^{\text {nd }}$ ed., pp. 690-694. Oxford: Elsevier.

Lillo-Martin, Diane and Richard Meier. 2011. On the linguistic status of 'agreement' in sign languages. Theoretical Linguistics 37(3-4): 95-141.

Meier, Richard. 2012. Language and Modality. In: Pfau, Roland, Markus Steinbach, and Bencie Woll (eds.). Sign Language: An International Handbook, pp. 574-601. Berlin: De Gruyter Mouton.

Meir, Irit. 2012. Word classes and word formation. In: Pfau, Roland, Markus Steinbach, and Bencie Woll (eds.). Sign Language: An International Handbook, pp. 77-111. Berlin: De Gruyter Mouton. 
Miles, Michael. 2000. Signing in the seraglio: mutes, dwarfs, and jesters at the Ottoman court 1500-1700. Disability \& Society 15(1): 115-134.

Neidle, Carol, Judy Kegl, Dawn MacLaughlin, Benjamin Bahan, and Robert G. Lee. 1998. The Syntax of American Sign Language. Cambridge, MA: MIT Press.

Nuhbalaoğlu, Derya and A. Sumru Özsoy. 2014. Linearization in NPs in TID. Paper presented at Formal and Experimental Approaches to Sign Linguistics Theory (FEAST), University of Venice.

Pfau, Robert and Josep Quer. 2012. Nonmanuals: their grammatical and prosodic roles. In: Brentari, Diane (ed.). Sign Languages, pp. 381-402. Cambridge: Cambridge University Press.

Pfau, Robert and Markus Steinbach. 2011. Grammaticalization in sign languages. In: Narrog, Heiko and Bernd Heine (eds.). The Oxford Handbook of Grammaticalization, pp. 683-695. Oxford: Oxford University Press.

Rathmann, Christian. 2005. Event Structure in American Sign Language. PhD Dissertation, University of Texas at Austin.

Sandler, Wendy and Diane Lillo-Martin. 2006. Sign Language and Linguistic Universals. Cambridge: Cambridge University Press.

Sapir, Edward. 1944. Grading: a study in semantics. Philosophy of Science 11(2): 93-116.

Sevinç, Müge. 2006. Grammatical relations and word order in Turkish Sign Language (TID). Master of Arts Thesis. Middle East Technical University, Ankara.

Sevinç, Müge and Cem Bozşahin. 2006. Verb Categories in TİD. Paper presented at ICTL, Uppsala University.

Stassen, Leon. 2006. Comparative Constructions. In: Allen, Keith (ed.). Encyclopedia of Language and Linguistics, $2^{\text {nd }}$ ed., pp. 687-689. Oxford: Elsevier.

Stassen, Leon. 2013. Comparative Constructions. In: Dryer, Matthew S. and Martin Haspelmath (eds.). The World Atlas of Language Structures Online. Leipzig: Max Planck Institute for Evolutionary Anthropology.

Stokoe, William C. 1960. Sign Language Structure: An Outline of the Visual Communication Systems of the American Deaf. (Studies in Linguistics: Occasional Papers, no. 8). Buffalo: Dept. of Anthropology and Linguistics, University of Buffalo.

Zwitserlood, Inge, Pamela Perniss, and Aslı Özyürek. 2013. Expressions of Multiple Entities in Turkish Sign Language. In: Arık, Engin (ed.). Current Directions in Turkish Sign Language Research, pp. 269-298. Newcastle upon Tyne: Cambridge Scholars Publishing. 